\title{
Distinct Localization of Collagenase and Tissue Inhibitor of Metalloproteinases Expression in Wound Healing Associated with Ulcerative Pyogenic Granuloma
}

\author{
Ulpu K. Saarialho-Kere, " Elise S. Chang, ${ }^{*}$ Howard G. Welgus, * and William C. Parks * \\ *Division of Dermatology, Jewish Hospital at Washington University Medical Center; and ${ }^{\star}$ Department of Pathology, Washington \\ University School of Medicine, St. Louis, Missouri 63110
}

\begin{abstract}
To examine the role of metalloproteinases in tissue remodeling associated with wound healing, we used in situ hybridization to localize the expression of collagenase and tissue inhibitor of metalloproteinases (TIMP) in samples of pyogenic granuloma. Strong hybridization for collagenase mRNA was detected in basal keratinocytes near the advancing edge of all ulcerative lesions, but no collagenase mRNA was seen in samples without ulceration. Distinct from the sites of collagenase expression, TIMP mRNA was detected in stromal cells and in cells surrounding proliferating vessels. No collagenase mRNA was found in the epidermis of healthy skin, although occasional stromal cells contained collagenase or TIMP mRNAs, and TIMP mRNA was detected in hair follicles and sebaceous glands. Our results suggest that basal keratinocytes adjacent to wounded epidermis are critically involved in matrix remodeling, much more so than adjacent or underlying dermal fibroblasts. Furthermore, as several reports have suggested, TIMP may play a role in angiogenesis. Finally, in contrast to findings from other models which indicate that collagenase and TIMP proteins are secreted by the same cells, our data also demonstrate that these proteins can be produced in vivo independently of each other. (J. Clin. Invest. 1992. 90:1952-1957.) Key words: tissue inhibitor of metalloproteinases $\bullet$ interstitial collagenase • wound healing • keratinocytes • pyogenic granuloma
\end{abstract}

\section{Introduction}

The family of matrix metalloproteinases has been implicated in the remodeling of extracellular matrix associated with wound healing, inflammation, and angiogenesis $(1,2)$. Together, these enzymes have the capacity to degrade most matrix components, and one member of this family, interstitial collagenase, has the unique property of being able to cleave the triple helix of native collagen types I, II, III, VII, and X $(3,4)$. Collagenase is produced in vitro by a variety of cell types including fibroblasts, endothelial cells, keratinocytes, macrophages, and chondrocytes (5), but, with notable exceptions (see below), the in vivo expression of collagenase and its association with pathological conditions is poorly understood. The activity of collagenase is regulated, in part, by tissue inhibitor of

Address correspondence to William C. Parks, Ph.D., Dermatology Division, Jewish Hospital, 216 S. Kingshighway Boulevard, St. Louis, MO 63110 1992.

Received for publication 9 March 1992 and in revised form 19 May

J. Clin. Invest.

(C) The American Society for Clinical Investigation, Inc.

$0021-9738 / 92 / 11 / 1952 / 06 \quad \$ 2.00$

Volume 90, November 1992, 1952-1957 metalloproteinases (TIMP). ${ }^{1}$ This glycoprotein inhibits collagenolytic activity by binding tightly and noncovalently to the active enzyme (6). TIMP is as well expressed in vitro by numerous cell types, including fibroblasts, chondrocytes, endothelial, and vascular smooth muscle cells (5).

Although collagenase and TIMP are often produced by the same cell types, it is not clear whether both proteins are usually synthesized by the same individual cells. In the few in vivo studies done, the two proteins do seem to be coexpressed by the same cells. For example, in synovial lining cells from patients with inflammatory arthropathies $(7,8)$ and in tissue adjacent to scars undergoing active remodeling (9), collagenase and TIMP are expressed in the same areas and probably within the same cells. However, in colonic anastomoses (10) and in resorbing tissues (11), TIMP and collagenase are occasionally found in separate areas suggesting distinct roles for the two proteins in a normal repair process. In addition, while many in vitro studies have found coordinate stimulation of collagenase and TIMP in response to cytokines and growth factors (1214), disparate regulation has been observed for glucocorticoids (15), retinoic acid (15), transforming growth factor $\beta$ (13), and interferon- $\gamma(16)$, suggesting that the two proteins are not always produced concomitantly.

Pyogenic granulomas are common, benign vascular growths characterized by a proliferation of endothelial cells and neovascularization (17). They occur mostly on the extremities and face and often have superficial ulceration. Although minor trauma and infections have been implicated in their etiology, the causative factor leading to the development of pyogenic granuloma is unknown. Occasionally, after surgical removal or trauma, local satellites appear around the primary lesion, but these often regress spontaneously (18).

In many respects, particularly the ulcerative and angiogenic characteristics, pyogenic granuloma is a model of wound healing. Since the production of collagenase and TIMP are increased in human dermis after wounding by suction blister formation (19), we examined 16 samples of pyogenic granuloma for expression of mRNAs coding for these proteins. Using in situ hybridization with ${ }^{35} \mathrm{~S}$-labeled RNA probes, we report that interstitial collagenase expression is induced in basal keratinocytes near the advancing edges of the ulcer while TIMP mRNA was detected in fibroblast-like cells within the center of lesion surrounding newly formed blood vessels. Thus, interstitial collagenase and TIMP are expressed in pyogenic granuloma by different cells and at different sites within the lesion. This strongly suggests that in skin diseases characterized by ulceration, keratinocytes may play a significant and even predominant role in collagen remodeling.

1. Abbreviation used in this paper: TIMP, tissue inhibitor of metalloproteinases. 


\section{Methods}

Tissues. 16 formalin-fixed, paraffin-embedded histological specimens of pyogenic granuloma were obtained from the Department of Pathology, Washington University School of Medicine, St. Louis, MO. In addition, five samples of normal skin from different parts of the body were examined.

Tissue preparation and in situ hybridization. In situ hybridization was done essentially as described (20). To minimize any accumulated RNase contamination, $\sim 5-10$ sections were cut and discarded from each archival block. Sections for hybridization were cut at $5 \mu \mathrm{m}$ on Superfrost Plus slides (Fisher Scientific Co., Pittsburgh, PA), deparaffinized in xylene, dehydrated through graded ethanols, and rehydrated in PBS. All sections were treated with $1 \mu \mathrm{g} / \mathrm{ml}$ nuclease-free proteinase K (Sigma Chemical Co., St. Louis, MO) to loosen the constraints of intracellular cross-links caused by aldehyde fixation and then washed in freshly prepared $0.1 \mathrm{M}$ triethanolamine buffer containing $0.25 \%$ acetic anhydride to reduce potential nonspecific binding sites. Sections were covered with $25-50 \mu$ l of hybridization buffer containing $50 \%$ deionized formamide, $2 \mathrm{X}$ standard saline-citrate buffer (SSC: $1 \mathrm{X}$ is $150 \mathrm{mM} \mathrm{NaCl}, 15 \mathrm{mM}$ sodium citrate, $\mathrm{pH} \mathrm{7.0),} 20 \mathrm{mM}$ Tris- $\mathrm{HCl}, \mathrm{pH}$ 8.0, $1 \mathrm{X}$ Denhardt's solution, $1 \mathrm{mM}$ EDTA, $10 \%$ dextran sulfate, 100 $\mathrm{mM}$ DTT, $0.5 \mathrm{mg} / \mathrm{ml}$ yeast tRNA, and $2.5 \times 10^{4} \mathrm{cpm} / \mu 1$ of ${ }^{35} \mathrm{~S}$-labeled RNA probe. To retain the hybridization solution, sections were covered with siliconized, autoclaved coverslips sealed with 1:10 mixture of petroleum ether and rubber cement. Sections were incubated at $55^{\circ} \mathrm{C}$ for $18 \mathrm{~h}$ in a humidified chamber.

After hybridization, slides were washed under stringent conditions as described (20) except that $10 \mathrm{mM}$ DTT was substituted for $25 \mathrm{mM}$ $\beta$-mercaptoethanol in the wash solutions. Nonspecific binding was reduced by incubating slides in $0.5 \mathrm{M} \mathrm{NaCl}, 10 \mathrm{mM}$ Tris- $\mathrm{HCl}, \mathrm{pH} 8.0,1$ $\mathrm{mM}$ EDTA containing $20 \mu \mathrm{g} / \mathrm{ml}$ RNase-A (Sigma) at $37^{\circ} \mathrm{C}$ for 30 min. Washed slides were dipped in Kodak NTB-2 emulsion prediluted $1: 1$ with distilled water and processed for autoradiography as described (20). After development of the photographic emulsion, slides were stained with hematoxylin-eosin.

Preparation of RNA Probes. A 550-bp EcoRV-SmaI fragment of the 5' end of human collagenase cDNA (21) and a 313-bp AccI-EcoRI fragment of the 5 ' end of human TIMP cDNA (22) were subcloned in Bluescript KS transcription vector (Stratagene Inc., La Jolla, CA). The constructs were linearized within the multiple cloning site (SmaI and Accl, respectively) to allow transcription of antisense RNAs of 550 (collagenase) and 320 (TIMP) nucleotides. As a control for nonspecific hybridization, sections in each experiment were hybridized with T77-SP6, a 500-nucleotide sense RNA transcribed from a bovine tropoelastin cDNA. In vitro transcribed RNA was labeled with $\alpha$ $\left[{ }^{35}\right.$ S ]UTP ( $>1,200 \mathrm{Ci} / \mathrm{mmol}$; DuPont-New England Nuclear, Boston, MA) and purified as described (20). Blank sections without added radioactivity were processed to estimate autoradiographic background signal. The specificity of the collagenase and TIMP probes for the appropriate sized mRNA has been shown (23). In addition, by Southern analysis, ${ }^{32} \mathrm{P}$-labeled collagenase antisense RNA probe hybridized specifically to denatured, full-length collagenase cDNA and not to fulllength stromelysin-1 cDNA (data not shown).

\section{Results}

16 lesions from different parts of the body were studied, and histopathological assessment had determined all samples to be pyogenic granuloma. These samples represent all cases presented at Washington University School of Medicine over a four year period. Of the 16 samples studied, 10 had inflammatory infiltration and ulceration (Table I). Of these, six were advanced lesions and four were less advanced as judged by the extent of stromal cellularity and neovascularization. Six samples were studied which presented with no ulceration nor prominent inflammation.
Table I. Pathologic Features and Distribution of Interstitial Collagenase and TIMP-1 MRNAs of the 16 Samples of Pyogenic Granuloma Used in These Studies

\begin{tabular}{ccccccc}
\hline & & & & \multicolumn{2}{c}{ TIMP-1 mRNA } \\
\cline { 5 - 6 } Sample & Ulceration & $\begin{array}{c}\text { Inflammatory } \\
\text { infiltration }\end{array}$ & $\begin{array}{c}\text { Collagenase } \\
\text { mRNA }\end{array}$ & Perivascular & Stroma \\
\hline & & - & - & - & - & - \\
$1-3$ & - & - & - & - & + \\
$4-6$ & + & + & + & + & + \\
$7-16$ & + & & & & \\
\hline
\end{tabular}

Adjacent sections were cut from paraffin-embedded archival samples of ulcerative pyogenic granulomas and were hybridized with ${ }^{35}$ S-labeled interstitial collagenase and TIMP antisense RNA probes. Interstitial collagenase mRNA was observed in epidermal keratinocytes near the advancing edge of the ulcer and at sites of reepithelialization in all 10 samples with such lesions and with inflammation (Fig. 1). The autoradiographic signal was greatest in epidermal cells within the area of ulceration and bordering the intact epidermis. The signal strength decreased progressively towards the intact epidermis. Keratinocytes in intact epidermis were consistently negative for collagenase mRNA. In addition, signal was mostly confined to the basal keratinocytes, while the more differentiated epidermal cells were typically negative (Fig. $1, C$ and $D, H$ and $I, M$ and $N$ ). In a few samples, a relatively weak signal for collagenase mRNA was detected in occasional fibroblast-like cells of the upper dermis in the vicinity of the ulceration (Fig. 1, $\mathrm{H}$ and $I, L, M$ and $N$, and Fig. $2 A$ ). Thus, collagenase mRNA was only seen in areas near the site of ulceration and principally in basal keratinocytes.

The pattern of TIMP expression was completely distinct and removed from the localization of collagenase mRNA (compare Fig. 2, $A$ and $C$, with $B$ and $D$ ). In all ulcerative lesions, no TIMP mRNA was detected in the epidermis. Rather, TIMP mRNA was consistently seen in two types of fibroblast-like cells in the center of the lesions within the areas of angiogenesis (Fig. 2, $B$ and $D$ ). Some TIMP-positive cells were spindle form, and the others had large, oval nuclei, fine chromatin pattern, and ample amphophilic cytoplasm. In contrast to the relatively confined expression of collagenase, the signal for TIMP mRNA was diffuse and was seen in numerous cells within areas of neovascularization and inflammation. Typically, TIMP mRNA was concentrated near the newly formed vessels, and in several instances, strong hybridization signal clearly surrounded and outlined proliferating blood vessels (Fig. 2, $E-H)$. Inflammatory cells, such as granulocytes and lymphocytes, were consistently negative for TIMP expression (Fig. 2, $E$ and $F$ ).

Although both collagenase and TIMP mRNAs were detected in all samples with prominent inflammation and ulceration, only signal for TIMP mRNA was seen in samples without ulceration. Distinct from the prominent and localized expression in ulcerative specimens, no collagenase mRNA was detected in any sample without inflammation and ulceration (Fig. 2 I). TIMP mRNA, however, was seen in fibroblast-like stromal cells in $3 / 6$ nonulcerative lesions (Fig. $2 J$ ). Expression of TIMP in these intact lesions differed from the ulcerative forms in that mRNA was detected only in stromal fibroblast- 

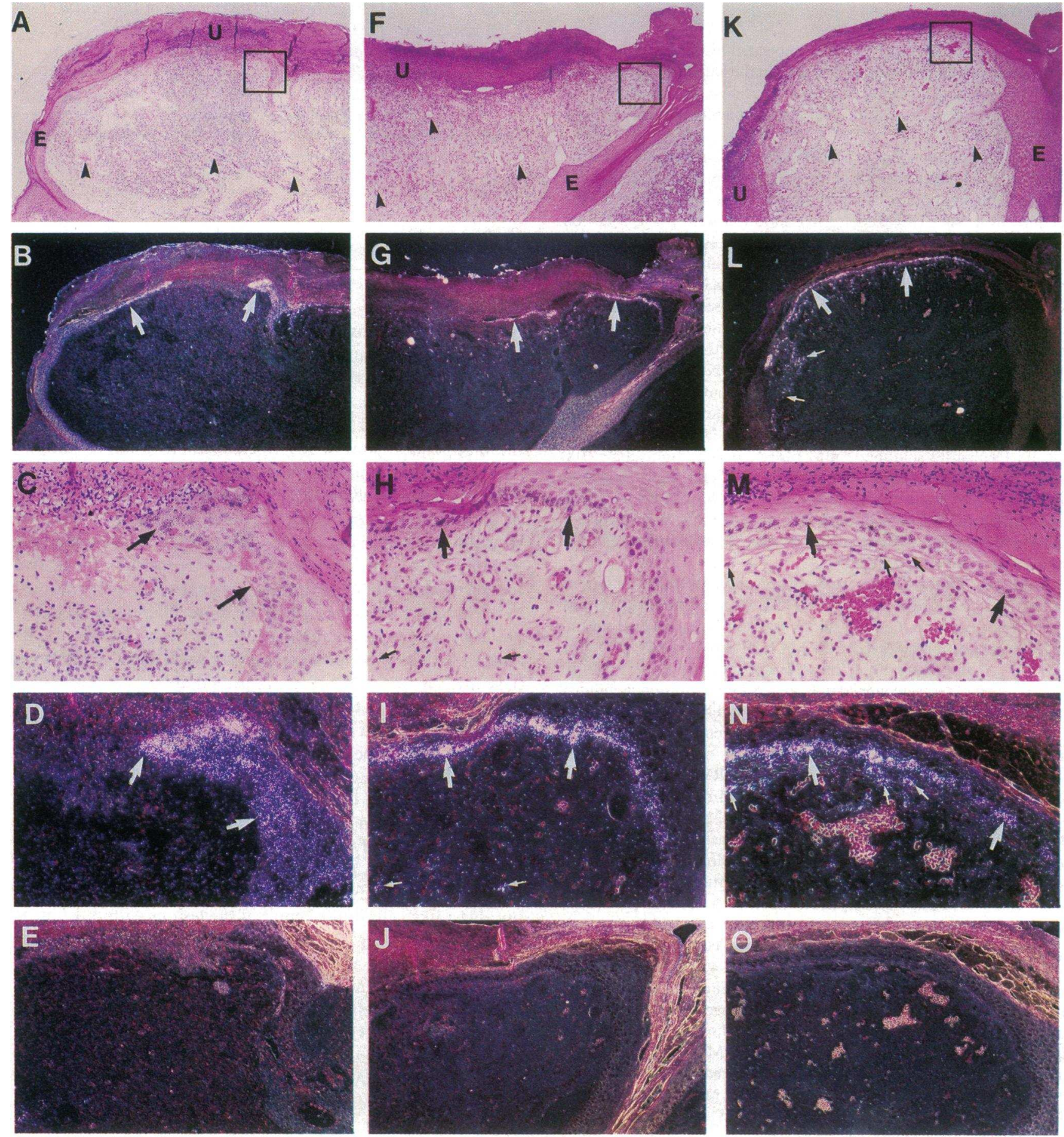

Figure 1. Localization of collagenase mRNA in ulcerative pyogenic granuloma. Sections of pyogenic granuloma with overt ulceration were hybridized with an antisense ${ }^{35}$ S-labeled RNA for interstitial collagenase mRNA or with sense RNA as described under Methods. Autoradiographic exposure was for $10 \mathrm{~d}$, and sections were stained with hematoxylin and eosin. Shown are the results from three specimens $(A-E, F-J$, and $K-O)$. In the low power, bright-field images $(A, F, K)$, prominent ulcerations are seen $(U)$, and regions of intact epidermis $(E)$ are evident away from the disrupted areas. Magnification, 80. On the right side of panels $F$ and $K$, invaginations of epidermis are seen. Numerous proliferating blood vessels (arrowheads) and regions of inflammation are also apparent in the center of all lesions. Paired dark-field photomicrographs $(B, G, L)$ reveal strong autoradiographic signal (large arrows) for collagenase mRNA in the epidermis surrounding the ulceration, and this signal diminishes as the epidermis becomes more intact. Under dark-field illumination, silver grains of the photographic emulsion appear white. Other components, especially the stratum corneum of the epidermis and erythrocytes, are noticeably iridescent under dark-field illumination. The boxed area in $A, F$, and $K$ are shown under higher magnification in panels $C$ and $D, H$ and $I$, and $M$ and $N$. Magnification, 400. Large arrows in the bright-field micrographs indicate basal keratinocytes that are positive for collagenase expression; small arrows $(H$ and $I, L, M$ and $N)$ indicate stromal fibroblast-like cells with a positive albeit weaker signal for collagenase mRNA. $(E, J$, and $O$ ) Signal specificity was demonstrated by hybridization with ${ }^{35}$ S-labeled sense RNA probe. The area shown in these control sections corresponds to the region in the above, higher magnification micrographs of sections probes with the antisense RNA. Magnification, 200. 

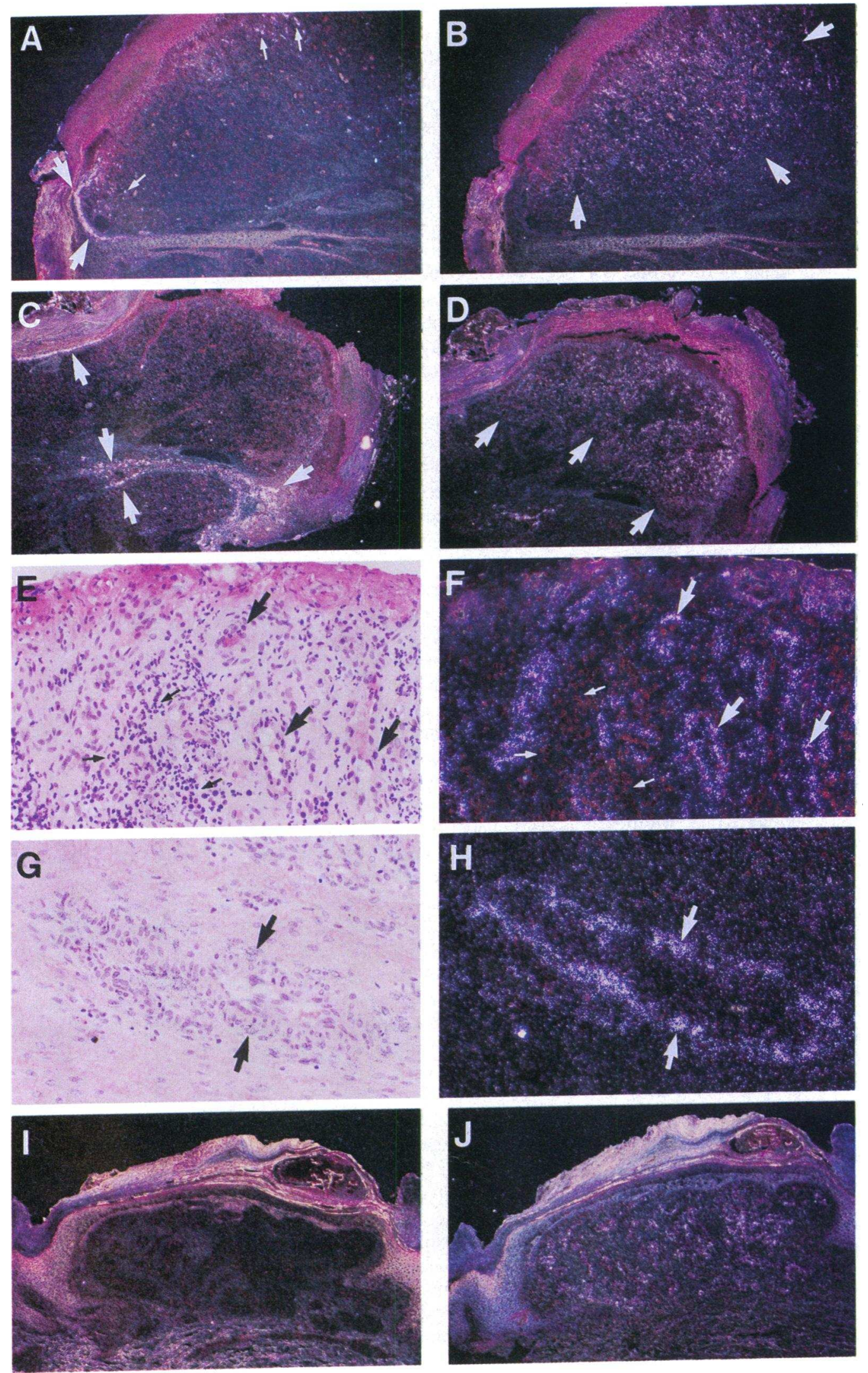

Figure 2. Localization of TIMP mRNA in ulcerative and nonulcerative pyogenic granuloma. ( $A-D$ ) Parallel sections from two ulcerative specimens were hybridized with antisense probes for collagenase ( $A$, $C)$ or TIMP $(B, D)$ mRNAs. As for the samples in Fig. 1, collagenase mRNA was mostly confined to basal keratinocytes (large arrows). In the lower section of $C$, signal for collagenase mRNA was seen on both basal sides of an invagination of the epidermis. In $A$, a few fibroblastlike cells in the stroma (arrows) were positive for collagenase mRNA (small arrows). TIMP mRNA localized to stromal areas (bordered by arrows) that were spatially distinct from those expressing collagenase. Magnification, 80. $(E-H)$ High power, paired bright- and dark-field micrographs of two ulcerative samples hybridized for TIMP mRNA. In both samples, the predominance of signal was localized to cells surrounding proliferating blood vessels (large arrows). In $E$ and $F$, numerous inflammatory cells were seen (small arrows) that were negative for TIMP mRNA. Magnification, 400. $(I, J)$ Parallel sections from a nonulcerative specimen were hybridized with antisense probes for collagenase $(I)$ or TIMP $(J)$ mRNAs. TIMP mRNA was seen in stromal cells within the center of the lesion, but no collagenase mRNA was detected. Magnification, 100. Autoradiographic exposure was $10 \mathrm{~d}$ for all samples in this figure.

like cells and was not seen in perivascular cells. No TIMP mRNA was found in the other three nonulcerative samples.

To determine if collagenase and TIMP are constitutively expressed in skin, we screened archival samples of normal skin from the face, arm, and leg for these transcripts. In agreement with previous immunohistochemical studies $(9,24)$, no inter- 
stitial collagenase or TIMP mRNA was detected in the epidermis of normal skin. In some samples, a small population of scattered fibroblast-like cells in the reticular dermis were positive for collagenase and TIMP mRNA (data not shown). TIMP expression was also seen in some hair follicles and sebaceous glands as reported by others (25).

The specificity of hybridization was demonstrated by the lack of any signal in sections probed with a ${ }^{35} \mathrm{~S}$-labeled sense RNA (Fig. 1, $E, J$, and $O$ ). Only background autoradiographic signal was seen in sections hybridized with this probe. For this control, we used a sense RNA, T77-SP6, transcribed from a bovine tropoelastin cDNA, and the validity of this probe as a negative control has been confirmed by Northern and in situ hybridization assays (20). The tropoelastin cDNA encodes an RNA that is $\sim 70 \% \mathrm{G} / \mathrm{C}(26)$ and, thus, under identical conditions, would have a greater propensity for nonspecific hybridization than the collagenase and TIMP probes, which are $\sim 43$ and $58 \% \mathrm{G} / \mathrm{C}$, respectively. Hence, the lack of signal on the negative control sections confirms the specificity of the signal detected with the collagenase and TIMP probes. Furthermore, sections processed for autoradiography without added probe had only background signal (not shown).

\section{Discussion}

Our results demonstrate that interstitial collagenase is expressed by basal keratinocytes near the advancing edge of ulcerative lesions in pyogenic granuloma (Table 1 ). Strong hybridization signal for collagenase mRNA was observed in every sample containing invaginating, disrupted epidermis adjacent to an ulceration. The specificity of this inductive response was demonstrated by the lack of hybridization signal for collagenase mRNA in cells of intact or normal epidermis. Interestingly, plasminogen activator mRNA and protein have been found in this same region in mouse wounds (27). Plasminogen is also released by damaged tissue, and its active form, plasmin, has been implicated in the in vivo activation of interstitial collagenase (28). Thus, cells near the site of a resorbing wound may express proteins necessary to degrade and remodel the adjacent stroma. Although collagenase mRNA was also detected in occasional fibroblast-like cells of the dermis near to the ulceration, this expression was appreciably weaker than the hybridization signal for collagenase mRNA in the basal epidermal cells. Thus, in this in vivo situation of wound healing, the basal keratinocyte seems to be the primary source of collagenase production and not dermal fibroblasts. Our results suggest that tissue remodeling is a significant function of keratinocytes in wound healing. The function of collagenase may be associated with repair and proliferation of the epithelium and with remodeling of dermal collagen. Since collagenase mRNA was not seen in nonulcerative pyogenic granulomas, the enzyme probably does not have a significant role related to angiogenesis or remodeling within the body of the lesion.

The signals that activate collagenase in keratinocytes and fibroblasts in response to wounding may be distinct. No interstitial collagenase mRNA was found in the epidermis of nonulcerative pyogenic granulomas. This suggests that collagenolytic activity may be induced with loss of epidermal basement membrane integrity thereby exposing keratinocytes to the underlying dermal stroma which may, in turn, influence keratinocyte phenotype (29). Consistent with this hypothesis, keratinocytes recognize and migrate on a type I collagen substratum, and this interaction results in enhanced collagenase synthesis (30). Keratinocyte contact with stromal matrix may be an important signal for inducing collagenase expression in ulcerative pyogenic granuloma. Indeed, only basal layer cells expressed collagenase mRNA and not the more differentiated cells of the stratum spinosum and stratum granulosum. By contrast, induction of collagenase expression in dermal fibroblasts may be mediated by soluble factors rather than influences from the extracellular matrix. Injury to skin augments release of interleukin-1 (31) which, in turn, may activate fibroblasts, but not keratinocytes (30), to produce collagenase. Moreover, macrophages produce cytokines, such as tumor necrosis factor- $\alpha$, which might also induce secretion of interstitial collagenase by resident fibroblasts (32).

TIMP may assist in wound healing by blocking or governing the degradation of fibrillar collagens, nonfibrillar collagens, laminin, proteoglycans, and elastin by susceptible metalloproteinases, namely interstitial collagenase, stromelysin, and 92$\mathrm{kD}$ type IV collagenase $(1,33)$. In our studies, TIMP mRNA was localized to dermal fibroblast-like cells present within the core of the lesion and usually surrounding proliferating blood vessels. Based on cell morphology, we cannot exclude that some TIMP-expressing cells in the stroma were macrophages. TIMP mRNA was not detected adjacent to ulcerative areas where its presence as a metalloproteinase inhibitor would be expected. Enhanced TIMP production may result from their stimulation by cytokines, such as transforming growth factor$\beta$, released from platelets or activated macrophages (34). Regardless, pyogenic granulomas are characterized by vascular proliferation, and we observed TIMP mRNA primarily around small, presumably newly formed blood vessels. Since TIMP has been reported to repress angiogenesis (35), it may be acting to control neovascularization in a manner distinct from inhibiting metalloproteinase activity. In support of this idea, TIMP stimulates keratinocyte growth on skin equivalents by a mechanism that is distinct from its function as a metalloproteinase inhibitor (36). Thus, it is possible that expression of TIMP in the areas of angiogenesis may occur in a role unrelated to the regulation of matrix remodeling.

The suggestion that TIMP in pyogenic granuloma is not associated with stromal degradation is further supported by its distinct sites of expression as compared to collagenase. Interstitial collagenase and TIMP are usually produced by the same cells in vitro, and their production is often controlled by the same regulatory modulators $(12-14,37)$. In vivo expression of collagenase and TIMP by the same cells has also been substantiated in arthritic synovial cells $(7,8)$ and hypertrophic scars (9). Coexpression, however, is apparently not an ubiquitous trait since our observations provide clear in situ evidence that the same cells do not elaborate these proteins in pyogenic granulomas. Alternatively, TIMP production apart from collagenase expression may indicate that the inhibitor is involved in governing the activity of other metalloproteinases.

In summary, our in situ hybridization studies show that collagenase expression is induced in basal keratinocytes adjacent to ulcerative lesions in pyogenic granuloma suggesting that these epithelial cells are involved in tissue remodeling associated with wound healing. Another unique aspect of this work is the demonstration that collagenase is produced in the epidermis and that its expression is spatially distinct from sites of TIMP expression. Our observations also suggest a role of TIMP apart from its function as a metalloproteinase inhibitor. 
Our future studies will be directed towards determining the physiologic inducer of collagenase production by keratinocytes during wound healing and evaluating whether the keratinocyte plays a predominant role in other types of skin repair.

\section{Acknowledgments}

We thank Dr. Gregory I. Goldberg, Washington University, for the human collagenase cDNA, and Dr. David Carmichael, Synergen Corp., Boulder, CO, for the human TIMP cDNA. We also express our appreciation to Drs. Mark Wick and Edmond Crouch for their pathology expertise, Darlene Stuart and Jill Roby for excellent technical assistance, and Louanne Davidson for secretarial assistance.

This work was supported by grants HL-41040, HL-29594, AR35805 and Training Grant AR-07824 from the National Institutes of Health. U. K. Saarialho-Kere is a recipient of a Dermatology Foundation Fellowship Award sponsored by Avon Products, Inc.

\section{References}

1. Matrisian, L. M. 1990. Metalloproteinases and their inhibitors in matrix remodeling. Trends Genet. 6:121-125.

2. Woessner, J. F. 1991. Matrix metalloproteinases and their inhibitors in connective tissue remodeling. FASEB (Fed. Am. Soc. Exp. Biol.) J. 5:21452154.

3. Welgus, H. G., J. J. Jeffrey, and A. Z. Eisen. 1981. The collagen substrate specificity of human skin fibroblast collagenase. J. Biol. Chem. 256:9511-9515.

4. Welgus, H. G., C. J. Fliszar, J. L. Seltzer, T. M. Schmid, and J. J. Jeffrey. 1990. Differential susceptibility of type $X$ collagen to cleavage by two mammalian collagenases and $72 \mathrm{kD}$ type IV collagenase. J. Biol. Chem. 265:1352113527.

5. Werb, Z. 1989. Proteinases and matrix degradation. In Textbook of Rheumatology. W. N. Kelley, J. Harris, S. Ruddy, and C. B. Sledge, editors. W. B. Saunders Co., Philadelphia. 300-326.

6. Welgus, H. G., and G. P. Stricklin. 1983. Human skin fibroblast collagenase inhibitor: comparative studies in human connective tissues, serum and amniotic fluid. J. Biol. Chem. 258:12259-12264.

7. McCachren, S. S. 1991. Expression of metalloproteinases and metalloproteinase inhibitor in human arthritic synovium. Arthritis Rheum. 34:1085-1093.

8. Firestein, G. S., M. M. Paine, and B. H. Littman. 1991. Gene expression (collagenase, tissue inhibitor of metalloproteinases, complement, and HLA-DR) in rheumatoid arthritis and osteoarthritis synovium. Quantitative analysis and effect of intraarticular corticosteroids. Arthritis Rheum. 34:1094-1 105.

9. Hembry, R. M., and H. P. Ehrlich. 1986. Immunolocalization of collagenase and tissue inhibitor of metalloproteinases (TIMP) in hypertrophic scar tissue. Br. J. Dermatol. 115:409-420.

10. Chowcat, N. L., F. J. Savage, R. M. Hembry, and P. B. Boulos. 1988. Role of collagenase in colonic anastomoses: a reappraisal. Br. J. Surg. 75:330-334.

11. Murphy, G., A. J. P. Docherty, R. M. Hembry, and J. J. Reynolds. 1991. Metalloproteinases and tissue damage. Br. J. Rheumatol. 30(Suppl. 1):25-31.

12. Murphy, G., J. J. Reynolds, and Z. Werb. 1985. Biosynthesis of tissue inhibitor of metalloproteinases by human fibroblasts in culture. Stimulation by 12-O-tetradecanoylphorbol 13-acetate and interleukin 1 in parallel with collagenase. J. Biol. Chem. 260:3079-3083.

13. Edwards, D. R., G. Murphy, J. J. Reynolds, S. E. Whitham, A. J. P. Docherty, P. Angel, and J. K. Heath. 1987. Transforming growth factor modulates the expression of collagenase and metalloproteinase inhibitor. $E M B O(E u r$. Mol. Biol. Organ.) J. 6:1899-1904.

14. Chua, C. C., and B. H. L. Chua. 1990. Tumor necrosis factor- $\alpha$ induces mRNA for collagenase and TIMP in human skin fibroblasts. Connect. Tissue Res. 25:161-170.

15. Clark, S. D., D. K. Kobayashi, and H. G. Welgus. 1987. Regulation of the expression of tissue inhibitor of metalloproteinases and collagenase by retinoids and glucocorticoids in human fibroblasts. J. Clin. Invest. 80:1280-1288.

16. Shapiro, S. D., E. J. Campbell, D. K. Kobayashi, and H. G. Welgus. 1990. Immune modulation of metalloproteinase production in human macrophages.
Selective pretranslational suppression of interstitial collagenase and stromelysin biosynthesis by interferon- $\gamma$. J. Clin. Invest. 86:1204-1210.

17. Lever, W. F., and G. Schaumburg-Lever. 1990. Tumors of vascular tissue. In Histopathology of the Skin. W. F. Lever and G. Schaumburg-Lever, editors. J. B. Lippincott Co., Philadelphia. 689-714.

18. Nappi, O., and M. R. Wick. 1986. Disseminated lobular capillary hemangioma (pyogenic granuloma). Am. J. Dermatopathol. 8:379-385.

19. Welgus, H. G., E. A. Bauer, and G. P. Stricklin. 1986. Elevated levels of human collagenase inhibitor in blister fluids of diverse etiology. J. Invest. Dermatol. 87:592-596.

20. Prosser, I. W., K. R. Stenmark, M. Suthar, E. C. Crouch, R. P. Mecham, and W. C. Parks. 1989. Regional heterogeneity of elastin and collagen gene expression in intralobar arteries in response to hypoxic pulmonary hypertension as demonstrated by in situ hybridization. Am. J. Pathol. 135:1073-1088.

21. Goldberg, G. I., S. M. Wilhelm, A. Kronberger, E. A. Bauer, G. A. Grant, and A. Z. Eisen. 1986. Human fibroblast collagenase. Complete primary structure and homology to an oncogene transformation-induced rat protein. J. Biol. Chem. 261:6600-6605.

22. Carmichael, D. F., A. Sommer, R. C. Thompson, D. C. Anderson, C. G Smith, H. G. Welgus, and G. P. Stricklin. 1986. Primary structure and cDNA cloning of human fibroblast collagenase inhibitor. Proc. Natl. Acad. Sci. USA. 83:2407-2411.

23. Sudbeck, B. D., J. J. Jeffrey, H. G. Welgus, R. P. Mecham, D. McCourt, and W. C. Parks. 1992. Purification and characterization of bovine collagenase and tissue inhibitor of metalloproteinases. Biochim. Biophys. Acta. 293:370-376.

24. Childers, J. W., A. D. Hernandez, J. H. Kim, and G. P. Stricklin. 1987. Immunolocalization of collagenase inhibitor in normal skin and basal cell carcinoma. J. Am. Acad. Dermatol. 17:1025-1032.

25. Kawabe, T. T., T. J. Rea, A. M. Flenniken, B. R. G. Williams, V. E. Groppi, and A. E. Buhl. 1991. Localization of TIMP in cycling mouse hair. Development (Camb.). 111:877-879.

26. Yeh, H., N. Ornstein-Goldstein, Z. Indik, P. Shepard, N. Anderson, J. C. Rosenbloom, G. Cicila, K. Yoon, and J. Rosenbloom. 1987. Sequence variation of bovine elastin mRNA due to alternative splicing. Collagen Relat. Res. 7:235247.

27. Romer, J., L. R. Lund, J. Eriksen, E. Ralf kier, R. Zeheb, T. D. Gelehrter, K. Dano, and P. Kristensen. 1991. Differential expression of urokinase-type plasminogen activator and its type-1 inhibitor during healing of mouse skin wounds. J. Invest. Dermatol. 97:803-811.

28. Werb, Z., C. Mainardi, C. A. Vater, and E. D. Harris, Jr. 1977. Endogenous activation of latent collagenase by rheumatoid synovial cells: evidence for a role of plasminogen activator. N. Engl. J. Med. 296:1017-1023.

29. Stoker, A. W., C. H. Streuli, M. Martins-Green, and M. J. Bissell. 1990. Designer microenvironments for the analysis of cell and tissue function. Curr. Opin. Cell Biol. 2:864-874.

30. Petersen, M. J., D. T. Woodley, G. P. Stricklin, and E. J. O'Keefe. 1990. Enhanced synthesis of collagenase by human keratinocytes cultured on type I or type IV collagen. J. Invest. Dermatol. 94:341-346.

31. Kupper, T. 1990. The activated keratinocyte: a model for inducible cytokine production by non-bone marrow-derived cells in cutaneous inflammatory and immune responses. J. Invest. Dermatol. 94(Suppl. 6):146S-149S.

32. Dayer, J. M., B. Beutler, and A. Cerami. 1985. Cachectin tumor necrosis factor stimulates collagenase and prostaglandin E-2 production by human synovial cells and dermal fibroblasts. J. Exp. Med. 162:2163-2168.

33. Senior, R. M., G. L. Griffin, C. J. Fliszar, S. D. Shapiro, G. I. Goldberg, and H. G. Welgus. 1991. Human 92-kilodalton and 72-kilodalton type IV collagenases are elastases. J. Biol. Chem. 266:7870-7875.

34. Wright, J. K., E. Cawston, and B. L. Hazleman. 1991. Transforming growth factor beta stimulates the production of the tissue inhibitor of metalloproteinases (TIMP) by human synovial and skin fibroblasts. Biochim. Biophys. Acta. 1094:207-210.

35. Takigawa, M., Y. Nishida, F. Suzuki, J. Kishi, K. Yamashita, and T. Hayakiana. 1990. Induction of angiogenesis in chick yolk sac membrane by polyamines and its inhibition by TIMP and TIMP 2. Biochem. Biophys. Res. Com mun. 171:1264-1271.

36. Bertaux, B., W. Hornebeck, A. Z. Eisen, and L. Dubertret. 1991. Growth stimulation of human keratinocytes by tissue inhibitor of metalloproteinases. $J$. Invest. Dermatol. 97:679-685.

37. Welgus, H. G., E. J. Campbell, J. D. Cury, A. Z. Eisen, R. M. Senior, S. M. Wilhelm, and G. I. Goldberg. 1990. Neutral metalloproteinases produced by human mononuclear phagocytes. Enzyme profile, regulation, and expression during cellular development. J. Clin. Invest. 86:1496-1502. 